University of Nebraska - Lincoln

DigitalCommons@University of Nebraska - Lincoln

Educational Psychology Papers and

Publications

Educational Psychology, Department of

9-20-2004

\title{
Home-School Collaboration
}

Richard J. Cowan

Kent State University, rcowan1@kent.edu

Susan M. Swearer Napolitano

University of Nebraska-Lincoln, sswearernapolitano1@unl.edu

Susan M. Sheridan

University of Nebraska-Lincoln, ssheridan2@unl.edu

Follow this and additional works at: https://digitalcommons.unl.edu/edpsychpapers

Part of the Educational Psychology Commons

Cowan, Richard J.; Swearer Napolitano, Susan M.; and Sheridan, Susan M., "Home-School Collaboration" (2004). Educational Psychology Papers and Publications. 18.

https://digitalcommons.unl.edu/edpsychpapers/18

This Article is brought to you for free and open access by the Educational Psychology, Department of at DigitalCommons@University of Nebraska - Lincoln. It has been accepted for inclusion in Educational Psychology Papers and Publications by an authorized administrator of DigitalCommons@University of Nebraska - Lincoln. 


\title{
Home-School Collaboration
}

\author{
Richard J. Cowan \\ Kent State University, Kent, Ohio
}

\author{
Susan M. Swearer and Susan M. Sheridan \\ University of Nebraska-Lincoln, Lincoln, Nebraska
}

1. Home-School Collaboration Defined

2. Background and History of Home-School Collaboration

3. Factors Influencing Home-School Collaboration

4. Approaches to Fostering and Maintaining Home-School Collaboration

5. Conclusion Further Reading

\section{GLOSSARY}

collaboration Working together toward a common goal or set of goals.

educators General education instructors, special education instructors, leaching aides, classroom volunteers, administrators, support staff, school psychologists, and any other persons within a school setting who contribute to the education of students within that environment.

parent The adult who is responsible for the care and wellbeing of the child (e.g., biological parent, caregiver, legal guardian). partnership A coequal interdependent relationship that is established and developed over time, with the primary purpose of working together over an extended period of time toward a mutually determined set of goals and objectives.

system A particular environment with an emphasis on specific components of the environment, including people, physical objects, placement of people and objects, physical arrangement, and interactions among these components (e.g., home system; school system).

Home-school collaboration is a reciprocal dynamic process that occurs between at least one parent (or guard- ian) and at least one individual within the school system (e.g., educators, administrators, psychologists) who share in decision making regarding mutually determined goals and solutions related to a student for whom all parties share interest and responsibility. Home-school collaboration may occur at three levels: system (i.e., between the home and school settings), school/classroom, and individual. With all participants (e.g., parents, educators) offering their unique roles and contributions, the collaboration process is guided by the primary emphasis on mutually determined academic and behavioral goals serving as the standard for progress toward overall outcomes.

\section{HOME-SCHOOL COLLABORATION DEFINED}

A common definition of the term "collaboration" is to work together toward a common goal or set of goals. As applied to relationships among parents, educators, and the systems in which they operate, the term has a rich meaning. Driven by academic, cultural, and political influences, the term "home-school collaboration" is a reciprocal dynamic process that occurs among systems (e.g., families, communities, partnerships), schools/ classrooms, and/or individuals (e.g., parents, educators, administrators, psychologists) who share in decision making toward common goals and solutions related to students. Inherent in this definition is the notion that parents and educators involved in collaboration pool their resources to create a cooperative interdependent re- 
lationship. For example, parents offer what they know about their children's academic and behavioral strengths and limitations in the home and other non-school settings, whereas teachers offer their knowledge of students' relative strengths and limitations in the classroom and other educational settings. The collaboration process is guided by a primary emphasis on specific cooperatively predetermined outcomes for students, with mutually established academic and behavioral goals.

\section{BACKGROUND AND HISTORY OF HOME-SCHOOL COLLABORATION}

\section{I. Traditional Family Involvement in Education}

During colonial times and throughout the early 19005, parents had very little interaction with the educational system. In 1995, Welch and Sheridan noted that during that time in educational history, children were sent to school to learn academic skills, and parents were seen as responsible for educating their children regarding moral principles in the home setting. Parents entrusted the education of their children to school personnel and expressed little interest in participating in their children's education. These expectations and roles resulted in educators viewing the school as their territory, and parents who tried to become an active part of the school setting were viewed as intrusive. In response to this situation, the National Parent-Teacher Association (PTA) was founded on February 17, 1897, in Washington, D.C., with the goal of having a PTA in every school. Today, there are more than 6.5 million members of the National PTA, making it the largest child advocacy organization in the United States.

Welch and Sheridan reported that parents continued to assume a relatively "hands-off" approach to education until the late 19605 and early 19705, when economic and political factors induced parents to change their views regarding their involvement in education. Fueled by economic situations that forced society to reconsider how money was being spent on education, as well as by a political climate in which legislation was identifying and defining specific roles for parents in their children's education, parents became more active in education. The National PTA continued to be a strong advocacy voice for parent involvement in education. In 1994, the federal government enacted "Goals 2000," and in 1997, the National PTA released its National Standards for Par-
ent/Family Involvement Programs. However, although parents advocated for participation in education, the educational system was not prepared for this type of parental involvement. Despite the efforts of the National PTA, when parents participated in education, their involvement was limited in both scope and depth. Unfortunately, parental involvement in education has continued to be limited. Many parents feel as though they are outsiders in their children's school. Merely opening the doors for parents to participate at an entry level is not enough. Epstein has written extensively about the need to develop family-school-community partnerships to enhance student performance. These partnerships reflect an important process that includes all families. The next subsection describes a philosophy to guide parental involvement in education: the home-school partnership model for working with families.

\subsection{Partnering With Families in Education: A Modern Approach to Collaboration}

The definition of home-school collaboration provided earlier is derived in part from the characteristics of a partnership philosophy for interacting with families in education. This philosophy represents the current standard for how parents and families can be included as a member of the educational system. A partnership philosophy regarding home-school collaboration recognizes that parents are invaluable members of the educational team. Just as educators and administrators are viewed as possessing educational information and expertise, parents are viewed as experts possessing equally critical information regarding the home system. When schools adopt this attitude, they are more likely to actively pursue meaningful parental participation in education. If parents .and educators adopt this philosophy, it affords parents equal status with the school regarding critical activities and decision making related to their children's education.

A primary difference between home-school collaboration and home-school partnership is that home-school collaboration implies a process related to a specific goal or set of goals that may be relatively short term (but not necessarily), whereas home-school partnership implies a long-term, ever-evolving relationship between parents and members of the school setting extending beyond time-limited problem solving and goal achievement. A partnership allows parents and educators to work together to improve the educational system such 
that it is possible for them to work toward preventing future problems, meaning that all students benefit from the partnership. Another characteristic of a partnership is that individuals learn from one another and pool together expertise and skills in support of a common focus, that is, improved education for all students. Goals and objectives remain at the heart of interactions between parents and educators as they form educational partnerships; however, with partnerships, these goals are likely to be more long term and more encompassing (e.g., creating a safe and diverse atmosphere that addresses the needs of all students). In addition, the quality of the partnership will depend heavily on the type of communication that occurs between parents and educators. Maintaining open communication is likely to make a meaningful contribution to a healthy balanced partnership.

When schools invest in building partnerships by seeking meaningful ways in which to involve parents, many can be considerably enriched. For example, instead of a traditional one-directional approach to parent-teacher conferences, a teacher might approach this event by asking for parental input regarding behavior patterns across nonschool settings and ask for ideas regarding potential solutions. Furthermore, if parents and teachers interact regularly outside of the designated parent-teacher conference time (e.g., through home-school notes, at school activities), conference time might be used more constructively to address goals and solutions that require face-to-face communication. A partnership is not formed and developed during one interaction or activity; rather, it is established and cultivated over time through multiple interactions during which parents and educators come to embrace the attitude and belief that meaningful relationships form the foundation of indepth, long-term collaboration.

\subsection{Potential Benefits of Home-School Partnerships}

There are many potential benefits of home-school partnership. For example, collaboration through partnership can enhance communication between parents and educators. In addition, home-school relationships provide an opportunity for parents and educators to better understand what occurs across settings, and this in turn allows for a greater overall understanding of children's backgrounds and current levels of functioning. Establishing a home-school partnership also allows for "joint ownership" of problems and concerns as well as joint commitment toward educational and behavioral goals for students. Parents and teachers may come to feel supported by each other as they work toward mutually determined goals. Working together also tends to improve relationships between teachers and parents as they begin to understand each other's perceptions regarding children's behavior across settings. In addition to these potential benefits for parents and educators, students may benefit from the process. For example, they may develop better attitudes toward school, improve their performance both in and out of the classroom (e.g., demonstrate higher rates of work completion at school while at the same time demonstrating an increase in homework completion), get along better with teachers and other school-based individuals, and improve specific academic skills (e.g., reading fluency). As with any relationship, the benefits of a partnership might not be immediate, and it will likely take time for all participants to yield such benefits.

\section{FACTORS INFLUENCING HOME-SCHOOL COLLABORATION}

The educational system in the United States has been heavily influenced by a systems-based approach to understanding and intervening with regard to the educational process. This approach is grounded in ecological theory. Based on the work of Bronfrenbrenner, ecological theory is concerned with the interaction between an individual and various contextual systems: the microsystem, mesosystem, exosystem, and macrosystem. The microsystem is concerned with the individual and his or her immediate environment (e.g., a child interacting in a particular classroom), the mesosystem involves the interrelation between major systems in the individual's life (e.g., between home and school), the exosystem is concerned with environments not directly related to the individual but still influencing his or her life (e.g., a parent's workplace), and the macrosystem includes overall cultural or subcultural patterns and influences (e.g., policies, federal and state legislation, national and global economic factors). This framework illustrates how systems influence, and are influenced by, one another, stressing that individuals do not exist in isolation; rather, each individual's interactions across and within systems are multifaceted and multidetermined over time. Homeschool collaboration is influenced by multiple factors, including (but not limited to) educational legislation, family characteristics, school-based variables, and com- 
munity-related influences. Factors across these systems are not mutually exclusive and are discussed in the following subsections.

\section{1. Educational Legislation}

Education in the United States has forever been changed due to federal legislation that ensures the right to a free and appropriate public education for all individuals, mandates the individualization of services for students with special needs, incorporates the provision of educational services in the least restrictive environment, provides guidelines for educational planning and programming, specifies procedures for identifying students with special. needs, highlights roles and responsibilities for local educational agencies, and mandates specific roles for parents in education. Such legislation has led parents, educators, politicians, and others concerned with education to consider how best to foster relationships between parents and educators. Furthermore, it has changed the ways in which parents are involved in their children's education. The following subsections discuss major legislative and political factors affecting how parents and educators operationalize and designate roles and responsibilities in education.

\subsubsection{Individuals with Disabilities Education Act}

The Individuals with Disabilities Education Act (IDEA) is the latest manifestation of the public education law called the Education for All Handicapped Children Act (EAHCA, also referred to as Public Law 94-142). A major emphasis of the 1997 reauthorization of IDEA is the inclusion of specific requirements regarding the active recruitment and participation of parents throughout the evaluation process. Specifically, school personnel are now required to (a) notify parents in advance to ensure that they will have the opportunity .to attend each meeting related to their children's educational programming, (b) schedule meetings at a mutually determined time and place (even in the home if necessary and appropriate), and (c) arrange other means of including parents if they are unable to attend the meeting (e.g., teleconferencing).

In addition to ensuring that parents are able to actively participate in meetings related to their children's educational programming, IDEA mandates and outlines several parental rights and responsibilities. Specifically, parents are entitled to input during evaluation, eligibility, and placement. That is, in addition to contributing to the pool of information that will be used during the assessment of their children and that may result in special education placement, parents are afforded an opportunity to voice their opinions and contribute to the final decisions when the teams (of which parents are key members) determine (a) eligibility (i.e., declare whether students meet the specific predetermined criteria for placement under a qualifying category of disability as defined in IDEA), (b) accommodations that will be necessary to meet students' individual needs (as determined by goals and objectives outlined in the students' teamgenerated individualized educational plans [IEPs]), and (c) placement (i.e., where children will receive their educational programming, e.g., resource room, general education classroom, some combination thereof) .

Once students are identified and placed under the umbrella of special education and related services, they are entitled to a reevaluation at least every 3 years from their initial or latest evaluation to determine whether they continue to meet eligibility criteria for services. Parental permission for reevaluation is mandatory. Parents are also entitled to receive regular reports on their children's progress, and parents may request changes to educational programming (i.e., revisions of children's IEPs) to address any lack of progress toward annual goals. This level of parent recruitment and participation is significantly different from the hands-off approach popular until the late 19605 and early 1970s described earlier. As such, this legislation represents a powerful impetus for change with regard to parent and teacher roles throughout the educational process.

\subsubsection{No Child Left Behind}

"No Child Left Behind" (Public Law 107-110) is the latest manifestation of the public education law called the Elementary and Secondary Education Act (ESEA). As with IDEA, No Child Left Behind designates roles and responsibilities for parents and educators that necessitate home-school communication and cooperation. Perhaps the most salient feature of this legislation is its emphasis on providing information to parents while at the same time holding schools accountable for the quality of education they provide to all students. In addition to mandating that schools provide information to parents regarding their children's individual progress, No Child Left Behind requires states and school districts to give parents information about the relative strengths of each school. Specifically, for each school, they must pro- 
vide achievement data (combining the performances of all students) broken out by race, ethnicity, gender, English-language proficiency, migrant status, disability status, and income status. If, on receiving this information, parents believe that their children are not receiving adequate services, they may opt to place the children in better performing schools or tap additional resources such as tutoring and after-school programs.

Although there are clear benefits to educators and administrators (e.g., they are able to have detailed information about each child from which they can adapt teaching techniques, they are able to determine what does and does not work and make decisions based on the data), the emphasis of this legislation is on protecting individual students, parents, and families through providing critical information and options. This legislation provides critical information for educational partners to use in making decisions regarding how to improve the quality and fairness of the educational system. It also provides equal access to information, ensuring that no party has the upper hand. As indicated earlier, equal participation is a defining characteristic of educational partnerships. In addition, Goal 8 of the 1999 National Education Goals report concerns parental participation and states, "By the year 2000, every school will promote partnerships that will increase parental involvement and participation in promoting the social, emotional, and academic growth of children." In addition to clauses mandating the types of information to which parents are entitled, No Child Left Behind includes clauses mandating that parents have the right and responsibility to be involved at the school, district, and state levels. Specifically, No Child Left Behind states that every school must have a written parent involvement policy developed with and approved by parents. If developed and executed properly, this policy affords parents much power in decision making and in determining educational policy at a local level. No Child Left Behind also calls for a schoolparent compact, developed with and approved by parents, that describes how educators and parents will build a partnership to improve student achievement. If a partnership philosophy guides this compact, it can open to doors to multiple levels and types of home-school collaboration, expanding and evolving over time.

No Child Left Behind has resulted in an increased emphasis on site-based management. Site-based management, an approach with a long history, is concerned with decentralizing decision making by transferring authority and resources from state- and district-level offices to more localized units such as governance councils, committees, and teams located within each school building. This transfer of authority and power to a local level affords educational partners the opportunity to consider the data generated by schools to meet mandate requirements of No Child Left Behind and to make budget- and curriculumrelated decisions at an individual school level. These sitebased management teams, often composed of principals, teachers, parents, and other professionals, make decisions regarding policies for the schools. This structure necessitates input from parents as decision-making team members. Similar teams exist at the district and state board levels, whereby parents are involved as active developers and monitors regarding school board functions as well as district- and statewide governing bodies.

No Child Left Behind embodies the state of the nation regarding the pivotal role that parents play in the education of their children. This level of parental involvement requires communication and collaboration between parents and school-based personnel As with IDEA. a complete discussion of No Child Left Behind related to homeschool collaboration is beyond the scope of this article. Specific components of the legislation were discussed previously as a means of describing the rights and responsibilities of parents in education as mandated by federal law. How parents respond to such roles varies considerably across individuals and is likely influenced by multiple factors. some of which are described in the next subsection.

\subsection{Home- and Family-Related Factors}

There are many family-related factors that may influence how a family interacts with educators. The quality of the interaction is perhaps most heavily influenced by the family's history with the school, including how the family has been received by the school in the past. For example, during past interactions with the school, was the school hierarchical. that is, acting as if the parents' presence was an intrusion? Alternatively, was the family made to feel comfortable in the school setting? Has the family been proactively involved with the school (i.e., not just when their child is in need of assistance)? Does the family have a child who has been identified as at risk for, or as an individual with, a specific disability? If so, how was the family included in the related meetings and educational programming sequence ? In general. the more positive the family's past experiences. the more likely the family is to feel accepted and welcomed as an educational partner. 
Other factors that can potentially influence the nature of home-school collaboration are found under the broad umbrella of family culture. As used here, culture extends beyond race and ethnicity to include factors such as acculturation level, beliefs, values, and expectations. Acculturation level is concerned with families' adjustment to the immediate culture when they are not originally from the United States or when they are new to a particular region of the country .If they come from a place where the educational system varies considerably from that in their new surroundings, it may take them time to adjust to the new local norms regarding parental involvement in education. Some families might not view their role as that of active participants and may leave the majority of decisions and actions to educators, whereas others might take an active directive role in working with educators. Family culture also includes beliefs, values, and expectations regarding education. and how to interact with the school system. Stemming from cultural, economic, and political influences, these factors are multidetermined. Regardless of whether families consist of first-time parents or parents who have been involved in the educational system long enough to witness significant changes in roles for parents in education, families will require time to adjust to their new roles.

\subsection{School-Related Factors}

The school is a dynamic system that is composed of multiple individuals and influenced by multiple forces . (e.g., culture, economic conditions, politics). When considering school-related factors that may influence the nature of home-school collaboration, it is important to take into account both variables related to individuals within the school and building-specific traits and characteristics. With regard to school personnel, these individuals acquire beliefs, values, and expectations that are influenced by a myriad of cultural, economic, and political influences. These beliefs, values, and expectations evolve over time and influence interactions with parents. In addition, just as parents' behaviors are influenced by past experiences with the school, teachers' behaviors are influenced by past experiences with parents and families.

In addition to factors related to individuals within the school, factors related to the school itself may affect the nature of home-school collaboration. Just as each family is unique in its history and culture, each school takes on an identity that makes it unique. For example, is the school public or private? The choice to send children to a private school may represent different values and have implications for how parents and educators interact. It is also true that the size and organizational structure of the school may influence the degree to which parents feel comfortable. In general, a .larger school is less personal, and this may cause parents to feel somewhat overwhelmed, resulting in less contact and collaboration with the school. The organizational structure also influences how parents interact with school personnel. For example, are teachers and administrators readily available? Are there individuals who take it on themselves to make regular contact with parents? Some school administrators may encourage teachers to maintain regular contact with parents, whereas others may value a topdown approach in which parent contact occurs through administrator-initiated actions and activities (e.g., newsletters, organized meetings). Some schools are warmer, more inclusive, and generally more family-friendly than are others. How a school "feels" to parents and students is influenced by multiple factors, and this makes pinpointing salient factors a challenge.

\subsection{Community-Related Factors}

Community factors that influence interactions between parents and educators are difficult to isolate given their identification across multiple systems. However, one cannot overlook the powerful influence of the community in shaping individual and systemic behaviors. Broadening the definition of cultural influences, the community system posits its own set of norms, values, and expectations regarding home-school collaboration. Behaviors, attitudes, and values transmitted from individuals in the home and school settings culminate to form a message that guides community behaviors and actions, and this in turn influences individual parents and teachers engaged in collaboration. These may be based on religious, political, or other influences and .may vary over time. In addition to influencing how parents and educators interact, the community has the power to support or hinder goals and objectives identified collectively by parents and educators. For example, if parents and teachers agree that having an after-school program might help to reduce problems related to latchkey children (i.e., children who care for themselves after school), will the community embrace this plan? Does it offer supports to make the vision a reality? Do role models exist in the community to encourage more advanced collaboration? Each commu- 
nity has a history that guides immediate behavior, which in turn affects future interactions between various systems and individuals. This broad-based system is pivotal and cannot be underestimated with regard to the power it has in guiding home-school interactions.

\section{APPROACHES TO FOSTERING AND MAINTAINING HOME-SCHOOL COLLABORATION}

\subsection{Underlying Assumptions, Roles, and Responsibilities}

Stemming from a myriad of cultural, economic, and political influences, the educational system has called on parents to actively participate in both the general and special education processes. Parents are increasingly becoming more actively involved in planning and decision making at the local, district, and state levels. In addition to participating in traditional activities such as parentteacher conferences and back-to-school nights, parental involvement occurs through volunteering, planning, and serving on various committees. In addition to these responsibilities, parents of children who are identified with specific disabilities are involved in the assessment and identification of their children's specific strengths and limitations as well as in co-constructing and facilitating their children's IEPs. Parent involvement also occurs in the home and community. When parents read with their children, observe and participate in play, and support homework completion, this type of parent involvement supports the education of their children. Identifying meaningful ways in which parents can participate in their children's education is a task assigned to both parents and educators. If parents and educators engage in an educational partnership, team members will collectively identify and use specific areas of expertise that each member brings to the collaboration process as they make progress toward a mutually determined set of goals and objectives. Furthermore, if a partnership philosophy guides home-school interactions, parents and educators will seek ways in which members of the school system can support the home system.

\subsection{How to Involve Families in Education}

Although state and federal legislation mandates specify roles, rights, and responsibilities for parents in education, they do not prescribe specific means for establishing relationships between the home and school settings.
Building a partnership is a complex process that does not follow a "cookbook" approach; rather, fostering this relationship is a process that must be approached with care based on a specific guiding philosophy. One such philosophy was described by Christenson and Sheridan, who in 2001 maintained that partnership is not an approach to home-school interactions; rather, it is a guiding philosophy for educators and parents as they attempt to build a meaningful long-term relationship. Specifically, these authors articulated four components necessary for building meaningful partnerships: approach, attitudes, atmosphere, and actions.

Approach is a means of interacting with families that embraces the values of both the home and the school in constructing the educational experiences of children. This is concerned with educators taking an approach with families that communicates their value, unique knowledge and skills, and necessity to be involved in education. When this approach is taken, it is assumed that parents will be involved in the school curriculum and that educators will support parents so that children are successful in the home setting. Attitudes are the perceptions that families and schools have of one another. This component is concerned with identifying strengths in partners, focusing on these strengths, and assuming a joint responsibility for students' development and education. Atmosphere is the overall climate set for families and educators. Finally, the actions component involves strategies for building long-term partnerships. Actions are not merely activities that include families in a passive manner; rather, they are intended to be behaviors that, over time, actively include families in the educational process. Perhaps the most salient feature of this model is its emphasis on the processes required to build relationships over time.

\section{CONCLUSION}

Cultural, economic, and political influences have created an educational system that values parental involvement in the education of all students. As parents and educators have adjusted to their evolving relative roles, they have engaged in home-school collaboration as a means of working together toward achieving mutually determined educational goals for all students. As parents, educators, and other professionals (e.g., school psychologists) have searched for a guiding philosophy regarding their approach to interacting with one another, many have adopted a partnership philosophy. Partnerships are long- 
term relationships based on the premise that coequal power and coequal participation are prerequisite conditions for meaningful collaborative endeavors. When this philosophy is adopted, parents and educators share resources, ideas, decision-making power, and ownership for mutually determined goals regarding both the homeand school-based educational curricula. Partnerships in education allow parents to be more intricately involved in school-based educational processes as a means of enhancing home-school collaboration. In addition, schools can assist parents with the home curriculum by participating in activities such as conjoint behavioral consultation and solution-oriented family-school collaboration. Partnerships, like all relationships, take time to form and require mutual cultivation to develop and evolve. However, they can result in both meaningful and effective educational and developmental outcomes for children and yield benefits that cannot be achieved when families and schools work in isolation. With the appropriate approach, atmosphere, attitudes, and actions, home-school partnerships can create an essential condition for optimal success.

See also these articles in the Encyclopedia of Applied Psychology: Consultation Processes in Schools; SchoolCommunity Partnerships

\section{Further Reading}

Carlson, C. I., Hickman, J., \& Horton, C. B. (1992). From blame to solutions: Solution-oriented family-school con- sultation. In J. S. Christenson, \&: J. C. Conoley (Eds.), Home-school collaboration: Enhancing children's academic and social competence (pp. 193-213). Silver Spring, MD: National Association of School Psychologists.

Christenson, S. L., \& Conoley, J. C. (Eds.). (1992). Homeschool collaboration: Enhancing children's academic and social competence. Silver Spring, MD: National Association of School Psychologists.

Christenson, S. L., \&: Sheridan, S. M. (2001). Schools and families: Creating essential connections for learning. New York: Guilford.

Epstein, J. L., Sanders, M. G., Simon, B. S., Salinas, K. C., Jansorn, N. R., \& Van Voorhis, F. L. (2002). School, family, and community partnerships: Your handbook for action (2nd ed.). Thousand Oaks, CA: Corwin.

Esler, A. N., Godber, Y., \& Christenson, S. L. (2002). Best practices in supporting home-school collaboration. In A. Thomas, \&: J. Grimes (Eds.), Best practices in school psychology (4th ed., pp. 389-412). Bethesda, MD: National Association of School Psychologists.

Minke, K. M. (2000). Preventing school problems and promoting school success through family-school community collaboration. In K. M. Minke, \&: G. C. Bear (Eds.), Preventing school problems-Promoting school success: Strategies and programs that work (pp. 377-420). Bethesda, MD: National Association of School Psychologists.

Telzrow, C. F., \& Tankersley, M. (Eds.). (2000). IDEA amendments of 1997: Practice guidelines for school-based teams. Bethesda, MD: National Association of School Psychologists.

Welch, M., \& Sheridan, S. M. (1995). Educational partnerships: Serving students at risk. Fort Worth, TX: Harcourt Brace. 